\title{
Residential Neighbourhoods, Perceived Social Support and Subjective Wellbeing
}

\author{
Olusegun Mayungbo, PhD \\ Retta Akingbade, PhD
}

Department of Sociology and Psychology, Faculty of Social and

Management Sciences, Lead City University, Ibadan, Nigeria

doi: 10.19044/esj.2017.v13n17p152 URL:http://dx.doi.org/10.19044/esj.2017.v13n17p152

\begin{abstract}
Research on subjective wellbeing has mainly focused on personality and demographic variables. The influence of residential neighbourhoods are usually not considered. This study, investigates the influence of types of neighbourhoods and perceived social support on life satisfaction among residents in Ibadan metropolis. Using a 2-way factorial design and multistage sampling technique, five of the eleven Local Government Areas (LGAs) in the metropolis were purposively selected for the study. Ten enumeration areas were selected from each LGA using simple random technique. The number of participants in the selected enumeration areas were determined using enumeration area maps. Two hundred and twenty house-owners and renters each were then selected from the low, medium and high density areas of the LGAs using systematic technique, making a total of 1,100 participants. The selected household heads were sampled. A structured questionnaire focusing on socio-demographic profile, life satisfaction scale ( $r=0.74)$ and a multi-dimensional scale of perceived social support $(\mathrm{r}=0.87)$ was administered to the participants. Data were analyzed using descriptive statistics and analysis of variance at 0.05 level of significance. Three hypotheses were tested. The results reveal that social support did not have significant main influence on life satisfaction $(\mathrm{F}(1,237)=.04 ; p>.05)$ while neighbourhood types significantly influenced life satisfaction $(\mathrm{F}(1,237)=$ $10.79 ; p<.05)$. There were significant interaction effects of neighbourhood and social support on life satisfaction $(\mathrm{F}(1,237)=4.15)$. The findings suggest that the places we live are important for improvement of our life satisfaction.
\end{abstract}

Keywords: Subjective wellbeing, residential neighbourhoods, social support, life satisfaction, happiness 


\section{Introduction}

Researchers have considered the standard of living of individuals to examine various choices residents make regarding the residential areas they reside in various cities in Africa. Findings have identified different reasons why people choose to dwell in their various neighbourhoods. According to Kauko (2006) people's choices are based on the amount of space available within a house. Alonso (1964) suggested that factors such as income, family size, population density, rent and transportation of households are deciding factors. Quingley (1985) identified the proximity of individuals' places of work as determinants. Croft (2003) believes such decision is based on available neighbourhood facilities while Cervero \& Duncan (2002) reported that travel time and location of house are considerations in choosing the neighbourhood to reside. However, whatever considerations or reasons households have for deciding where they reside, the places where individuals live are capable of either increasing or decreasing their levels of subjective wellbeing or life satisfaction.

Subjective wellbeing is a concept that individuals and policy makers continuously work towards improving, even though it lacks a universally acceptable definition. Subjective wellbeing is usually used interchangeably with life satisfaction, happiness and quality of life (Veenhoven, 2009). Subjective wellbeing comprises three dimensions, these are pleasant feeling, unpleasant feeling and life satisfaction, which is satisfaction in different aspects of life i.e. housing, the environment, health, leisure, etc. (McCrea,Marans,Stimson \& Western, 2011; De Vos,Schwanen,Van-Acker \& Witlox, 2013). Subjective wellbeing refers to how well individuals are living and flourishing (Tov \& Diener,2007). Subjective wellbeing is also an important indicator of personal health and quality of life and it is an appropriate standard for making public policies (Frey \& Stutzer 2012). Helliwell, Layard and Sachs (2013) observed that several international organizations and governments now adopt subjective well-being for assessing how effective public policies are, as well as for formulating better policies to improve the lives of the citizens. Studies on subjective wellbeing have also been used to explain the choices and behaviours of individuals (Deutsch-Burgner, Ravualaparthy \& Goulias,2014).

The study of subjective wellbeing from different disciplines has recorded different findings across nations (Veenhoven,1993). This suggests that the determinants of subjective wellbeing are not universal but vary with culture, place and time (Nordbakke \& Schwanen 2013). Ho, Cheung and Cheung (2008) noted that objective life conditions and situations can determine one's level of subjective wellbeing. The implication is that satisfaction is derived from major areas of life such as housing, neighbourhood, health, leisure, etc. It is therefore suggested that some events 
or situations could be important determinants of life satisfaction. Berry and Okulicz-Kozaryn (2011) have identified the choice of neighbourhood where one resides as one of the factors that improves subjective wellbeing. The deciding factor in judging the status of a particular neighbourhood is in its being exclusive. This is based on the fact that where individuals reside will influence many decisions regarding the types of people one interacts with, the type of schools available to one's children, etc. Galster and Killen (1995) argued that neighbourhoods possess major opportunities for children and even adults. Therefore, living in an exclusive neighbourhood is an indication of social standing and prestige and implies that such individuals have reached the top of the social ladder. Raising one's children in an exclusive neighbourhood increases the chances of the children reaching the top of the ladder as well.

Social comparison theory by Festinger (1954) can be used to explain differences in subjective wellbeing as well as the effects of the social environment on satisfaction with different aspects of life. The theory suggests that individuals compare themselves to other people, such as their neighbours, to reduce uncertainties in certain areas of life and to define the self. Luttmer (2005) noted that having higher income-earning neighbours is associated with lower levels of life satisfaction while having a better status than one's neighbours is linked to higher levels of life satisfaction (Dittmann \& Goebel 2010). Neighbourhood may influence a resident's subjective wellbeing through the social comparison effect (Layard 2005). Social comparison can be upward or downward. Upward comparison is to compare oneself with people who are superior while downward comparison is comparing oneself with someone worse off (Gibbons \& McCoy, 1991). For instance, if an individual living in an exclusive residential neighbourhood is low on wellbeing, downward comparison with other people living in a lower category neighbourhood can enhance such an individual's self-image and subjective wellbeing. Discrepancy theory implies that individual's subjective wellbeing is influenced by whether the place where an individual resides meets the individual's needs or aspirations (Kahana, Lovegreen, Kahana \& Kahana, 2003). Based on these theories, one might expect that people will be less satisfied if their neighbours or other neighbourhoods are perceived to be better than their own.

Residential neighbourhoods in Ibadan metropolis, the south-west of Nigeria are classified into high, medium and low-density areas (Ayeni, 1982). Accordingly, there are noticeable inequalities in the various neighbourhoods as well as the living conditions of residents (Dung-Gwom, 2007; Mallo \& Anigbogu, 2009). Low-density neighbourhoods are planned, high class choice reserved areas, where the majority of decent houses and massive structures are located; and residents with high social economic 
status are found. Such neighbourhoods have low population and low housing density as well as better facilities compared to medium and high density neighbourhoods. The high density neighbourhoods are usually unplanned areas where majority of residents that fall within the low socio-economic group are concentrated. The medium density is a mixture of the characteristics of both high and low densities. The high-density neighbourhoods in Nigeria are characterized by high population and high housing density where good roads, pipe borne water and so on are lacking. Therefore, high density neighbourhoods in Nigeria could be classified as disadvantaged neighbourhoods. There have been some concerns about the existing inequalities as well as the way in which many neighbourhoods, especially in the cities, have been neglected by policy makers. In the study of urban cities in Nigeria, Olajuyigbe, Osakpolor and Adegboyega, (2013) reported that the quality of life of Benin City was below average. Asiyanbola, Raji and Shaibu, (2012) noted that neighbourhoods' livability in Ago-Iwoye and Ijebu-Igbo towns in Ogun State, was below standard. Ilesanmi (2012) also observed that the quality of public housing in Lagos State was of low quality. These findings show that necessary facilities and amenities in these areas are in deplorable condition.

Perceived social support refers to the expectation that support will be provided rather than the actual situation of received support. Generally, the perception that social support is readily available has been linked with better outcomes in times of stress (Sarason, Sarason \& Gurung,1997). Newsom and Schulz (1996) assert that increased perceived social support is associated with increased life satisfaction and reduced symptoms of depression. Many researchers have indicated that perceived social support is positively related to life satisfaction (Lyubomirsky, 2007; Yeung \& Fung, 2007). Diener, Lucas \& Schimmark, (2008) went further to argue that receiving social support improves happiness better than personality factors. According to Berman, Heiss \& Sperling, (1994) the attachment theory of social support views attachment as being strongly occupied with the desire to have contact with the attachment figure. Summer and Knight (2001) suggested that individuals who have attachment relationships are more likely to have positive experiences which flow between the home and the workplace. Vasquez, Durik and Hyde (2002) found that individuals with less secure attachment reported less pleasant experiences about their family life and parenting than those who experience secure attachment relationship. Numerous studies have suggested the positive effects of social support on the quality of lives of individuals in latter years (Pinquart \& Soerensen, 2000; George, 2006; Sharma \& Malhotra, 2010; Thomas, 2010)). However, not all social relationships are beneficial to individuals (Adewuya, Afolabi, Ola, Ogundele, Ajibare, Oladipo, \& Fakande, (2010). Lyyra \& Heikkinen, 
(2006) contend that some social relationships might actually encourage adolescents to get involved in unhealthy behaviours, such as alcoholism, smoking and drug use. In addition, DiMatteo (2004), reported that social support can enhance stress.

Although studies have shown that perceived social support is capable of having positive effects on an individual's mental health (Zunzunegui, Alvarado, Del-Ser \& Otero, 2003; Young, Russell \& Powers, 2004), only a few studies have investigated the effects of individuals' interaction with their neighbours and their neighbourhood social environment (Wethington \& Kavey, 2000). Neighbourhoods are important for all residents but more important for older and retired residents, who are always at home (Horgas, Wilms, \& Baltes, 1998). The social aspect of neighbourhoods may be connected to the maintenance of positive social interaction with neighbours, maintaining closeness with neighbours and having a sense of attachment to the neighborhood. These various contacts with neighbours may increase social involvement and well-being (Wethington \& Kavey, 2000). According to Peirce, Frone, Russell, Cooper \& Mudar_(2000), having increased contact with neighbours can increase the overall social support, attachment to the neighbourhood and satisfaction. High levels of perceived support from neighbours, in turn, has been associated with fewer functional limitations in older adults (Shaw, 2005). Evidently, from the above, it is logical to assume that neighbourhood could interact with social support to improve the level of life satisfaction of residents.

In conclusion, extensive review of literature has shown that existing studies are mostly focused on the quality of houses, urban cities or health related satisfaction. However, there is still limited research evidence to demonstrate how types of neighbourhoods in urban areas affect the subjective well-being of its residents (Ballas \& Dorling 2013). The influence of neighbourhoods are not usually considered in most life satisfaction studies. Most studies of subjective wellbeing are usually focused on demographic, socio-economic and personality variables (Dolan, Peasgood \& White, 2008). Also, not many studies have examined the moderating effect of residential neighbourhoods and perceived social support on subjective wellbeing or life satisfaction. Despite the numerous studies previously conducted on life satisfaction, it is evident that past findings were not conclusive. Against this background, the present study investigates the influence of types of residential neighbourhoods and perceived social support on life satisfaction. The following research questions are raised: Will types of neighbourhoods independently influence life satisfaction? Will perceived social support independently influence life satisfaction? Will type of residential neighbourhood interact with perceived social support to influence life satisfaction? This study therefore investigates the main and 
interaction effect of types of neighbourhoods and perceived social support on life satisfaction. One major contribution of this study would be the implication of its findings for policy making, regarding residential neighbourhoods and social assessment of individuals on life satisfaction.

Based on review of literature, three hypotheses were generated:

1. Types of neighbourhoods will significantly independently influence life satisfaction.

2. Perceived social support will significantly independently influence life satisfaction.

3. Types of neighbourhoods will significantly moderate the effect of social support on life satisfaction.

\section{Methods}

\section{Research Design}

The study design was a 2-way factorial design. The independent variables in the study are types of neighbourhoods (high, medium and low) and social support (high and low).The dependent variable is life satisfaction. The study took place in 50 enumeration areas across five major Local Government Areas(LGAs) in Ibadan metropolis. Ten enumeration areas were selected through systematic random sampling from each of the five major LGAs.

\section{Sampling Procedure}

A multistage sampling method was adopted for the study. The first stage involved obtaining the list of all Local Government Areas (LGAs) in Ibadan metropolis from the Ministry of Lands and Housing. Five major LGAs were selected from the existing eleven LGAs, using purposive sampling method. The second stage involved obtaining the list of enumeration areas (EAs) for the selected LGAs from the National Population Commission (NPC). Random selection of $50 \mathrm{EAs}$, that is, ten EAs from each LGA was done as follows: assigning numbers to the EAs, calculating the sample fraction, randomly selecting the first EA and finally selecting every nth on the list for the remaining EAs, based on sample fraction. Stage three was the point at which the EA maps for the selected areas were obtained from the National Population Commission to determine the number of houses and their locations in the selected EAs in each of the LGAs. The fourth stage involved random selection of households among the houses identified from each EA by picking and marking every other household. Balloting was done to select a household where there were blocks of flats. The last stage was the sampling of all heads of households residing in the marked houses. 


\section{Participants}

A total of 1100 participants were randomly selected from the five major LGAs of Ibadan metropolis. Two hundred and twenty participants were sampled in each LGA, making a total of 1100 participants of which only 1012 questionnaires were returned. Participants consisted of houseowners and renters drawn from the high, low and medium density areas of the five major LGAs. The participants' age range was $42.11 \pm 15.20$ years. Of these, 443 (43.8\%) of the participants were males while 569 (56.2\%) were females. 242 (31.9\%) participants were house-owners while 690 (68.1\%) were renters. 182 (18\%) participants were from the low density, 282 (27.9\%) were from the medium density while 548 (54.1\%) participants were drawn from the high density neighbourhoods.

\section{Research Instrument}

The instrument was a structured questionnaire which collected data on socio-demograhic characteristics, perceived social support, and life satisfaction. Data on socio-demographic characteristics included age, gender, religion, occupation, marital status, ethnic group, educational status, house-ownership status, how long participants have owned their houses, type of house, type of ownership, type of neighbourhood and number of houses owned elsewhere. Perceived social support was measured with a 12 item Multidimensional Scale of Perceived Social Support (MSPSS) developed by Zimet, Dahlem, Zimet and Farly (1988). The Cronbach alpha reported ranged from 0.85 to 0.91 . Life satisfaction was measured by a 20 -item scale developed by Neugarten et al (1961). It has 3 response formats which are disagree, agree and don't know. The Cronbach alpha reported ranges from 0.79 to 0.90 .

\section{Procedure for data collection}

Random selection of enumeration areas within five major Local Government Areas (LGAs) was done with the help of seven experienced staff members of the National Population Commission. Enumeration area maps were used to identify the selected enumeration area boundaries. Having randomly selected houses in the enumeration areas, households were in turn identified. Letters of introduction were presented to the heads of households of each of the selected houses. Participants were informed that the purpose of the exercise was purely academic and therefore the confidentiality of their responses was guaranteed. The researcher sought their permission to mark their houses with chalk before the commencement of the administration of questionnaires. Having agreed to participate in the study, participants were requested to sign consent forms before questionnaires were administered to them. Questionnaires were administered under the condition of anonymity. 
Some questionnaires were not properly completed and were discarded. Out of the one thousand one hundred questionnaires administered, only one thousand one hundred and twelve were completed and returned. The completed copies were analyzed with the Statistical Package for the Social Sciences (SPSS) software.

\section{Analysis}

The statistics used in this study was a $2 \times 3$ analysis of variance (ANOVA).

Table 1. Summary of 2 x 3 ANOVA showing main and interaction effects of neighbourhood types and social support on life satisfaction.

\begin{tabular}{cccccc} 
Source & SS & Df & MS & F & P \\
\hline Neighbourhood type & 555.49 & 2 & 277.75 & 16.77 & $<.05$ \\
Social support & .42 & 1 & .42 & .03 & $>.05$ \\
Neighbourhood /Social support & 283.49 & 2 & 141.75 & 8.56 & $<.05$ \\
Error & 16612.95 & 1003 & 16.56 & & \\
Total & 17522.83 & 1008 & & &
\end{tabular}

Results from Table 1. demonstrate that neighbourhood types had a significant main influence on life satisfaction $(\mathrm{F}(2,1003)=16.77 ; p<.05)$ while social support did not influence life satisfaction $(\mathrm{F}(1,1003)=0.3$; $p>.05)$. However, there was an interaction effect of neighbourhood types and social support on life satisfaction $(\mathrm{F}(2,1003)=8.56, p<.05)$. The results reveal that neighbourhood type moderated the influence of social support on life satisfaction.

\section{Estimated Marginal Means of LIFE_SATISFACTION}

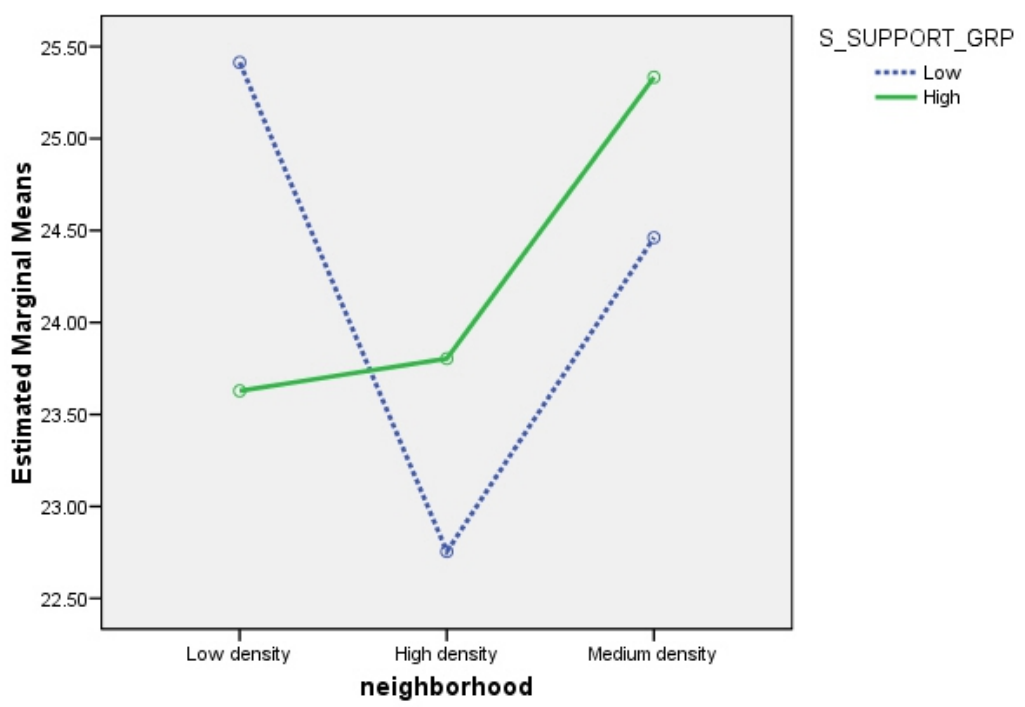


The graph indicates an interaction effect of types of residential neighbourhoods and perceived social support on life satisfaction. Participants residing in low density neighbourhoods who had low social support reported higher level of life satisfaction than participants who reside in the high density neighbourhoods and had high social support.

\section{Discussion}

The results reveal that residential neighbourhoods have a significant main effect on life satisfaction while social support has no main effect on life satisfaction. However, types of neighbourhoods interacted with perceived social support to influence life satisfaction. The analysis shows that participants living in low density neighbourhoods reported more satisfaction with life than participants in the high and medium density neighbourhoods. These results are in line with Dittmann \& Goebel (2010) \& Ludwig, Duncan, Gennetian,Katz and Kessler (2012) who found that people living in neighbourhoods with different socio-economic situations tend to have varying levels of life satisfaction. Sanni \& Akinyemi (2009) identify the quality of the environment, adequate planning with necessary infrastructural facilities, security of land ownership, neighbourhood safety, quietness of the environment, with adequate security, as the most important determinants of a household's neighbourhood choice in the low density areas of Ibadan metropolis.

These findings are also consistent with Oswald and $\mathrm{Wu}$ (2010) who reported that individuals living in places with pleasant features were more satisfied than residents of places with unpleasant features. Ibem and Amole (2013) identified satisfaction with the sizes of main activity areas of people's residents, management of the housing estate, privacy and the cost of housing as predictors of residents' life satisfaction. Leyden (2011) suggested that specific places in the built environment and maintenance of these places were associated with happiness. Shuhana, Rasyiqah \& Fatimah (2012) observed that high quality of living will affect citizen's lifestyle, health condition and the stability of the built environment. Many studies have submitted that community facilities, which most of low density residents are able to provide for themselves, play the role of creating healthy communities, enhancing wellbeing, building social networks and providing resource for training, employment and personal development (Vizec, 2010; Robinowitz, 2012; Emmanuel \& Akinbode, 2012).

Other researchers have documented other factors, such as, the level of urban economic advancement (Florida, Mellander \& Rentfrow, 2013), social interaction and cohesiveness of the neighbourhood (Dittmann \& Goebel 2010) and perceived neighbourhood safety (Poon \& Shang 2014) as positively associated to residents' life satisfaction. Pedersen and Schmidt 
(2011) argued that living in a deprived or an unsafe neighborhood with the likelihood of crime or vandalism is detrimental to life satisfaction. Aminzadeh, Denny,Utter,Milfont, Ameratunga,Teevale \& Clark, (2013) noted that neighbourhood deprivation is negatively associated with the wellbeing of young people. Unger (2013) observed that areas of broad economic and social disadvantage tend to have higher under-five mortality compared to socially and economically advantaged areas. Becares, Cormack \& Harris (2013) suggested that addressing neighbourhood poverty and area deprivation is essential to improving health outcomes of individuals. Shields, Wheatley \& Wooden (2009) found that the percentage of migrants and the poor in the neighbourhood is related to lower life satisfaction. Morrison (2011) contend that living in highly populated urban environments reduces subjective well-being.

The difference in the reported level of life satisfaction between low density neighbourhoods and high density neighbourhoods may therefore be due to the fact that participants in low density neighbourhoods enjoy better amenities than their counterparts in the high and medium density neighbourhoods, such as, accessibility, opportunities, less congestion, a high number of educated neighbours, high number of employed neighbours, better neighbourhood cooperation, better neighbourhood security, better condition of houses, better refuse and traffic control and better degree of social relationships within the neighbourhood. All these neighbourhood features which participants in the high and medium density neighbourhoods may not have access to, may positively influence their level of life satisfaction. According to Ekop (2012) socio-economic development and neighbourhood features are essential determinants of the livability of the Calabar metropolis (Aremu, Lawoko,Moradi \& Dalal, 2011; Boco, 2010). Sirgy and Cornwell (2002) reveal that the extent of available amenities and the level of civility within a neighbourhood can improve life satisfaction. They contend that the neighbourhood's physical, social and economic features, especially satisfaction with physical features such as, landscape, street lights, crowding, noise level, nearness of neighbourhood to needed facilities and the quality of the environment in the community, contribute to both neighbourhood satisfaction and housing satisfaction.

Lower life satisfaction has also been explained by residing in high poverty neighbourhoods and experiencing unfair treatment in such areas (Schulz, Williams, Israel, Becker \& Parker,2000). Therefore, living in the low density areas, can positively affect the life satisfaction level of residents in low density neighbourhoods. In addition, unlike majority of participants in high density neighbourhoods, participants in low density neighbourhoods are usually people of high socio economic status in high paying jobs, sometimes their major expenses are the responsibility of their companies in addition to 
their huge income and comfortable life style. Therefore, their high quality of life, and their environment may influence their life satisfaction. This confirms the position of Dietz (2002) who believes that socio-economic outcomes such as welfare, employment, health etc. are affected by where we live.

The significant interaction effect of types of neighbourhoods and perceived social support on life satisfaction is consistent with Sirgy \& Cornwell (2002) who identified satisfaction with neighbourhood social features such as social interactions with neighbours, people living in the neighbourhood, ties with people in the community, community crime rate, sense of privacy at home etc. significantly affects life satisfaction. Ostir, Eschbach, Markides \& Goodwin_(2003) also noted that the beneficial effects of social support may be important in neighbourhoods of low socio economic status people, where it may help to reduce the effects of neighbourhood poverty and related environmental stressors.

\section{Conclusion and recommendation}

This study found no main effect of social support on life satisfaction but there was a significant main effect of types of neighbourhoods on life satisfaction. The findings also revealed a significant interaction effect of types of neighbourhoods and social support on life satisfaction. Participants residing in the low density neighbourhoods reported better level of life satisfaction than those living in both the high and medium density neighbourhoods.This implies that where we live as individuals is important for our level of life satisfaction. The result of this study has shown the significant independent influence of types of neighbourhoods on life satisfaction. Types of neighbourhoods and social support were also found to have interaction effect on life satisfaction in this study. This suggests that participants' residential neighbourhoods should be considered when considering their improvement of life satisfaction. It is therefore recommended that policy makers should pay attention to the deplorable state of residential neighbourhoods especially the high and medium density areas. More low density neighbourhoods should be provided to enhance good quality living and consequently life satisfaction. Neighbourhood facilities should be adequately provided and maintained by the appropriate agencies of government rather than by the residents. Subjective wellbeing experts should also consider the importance of individual's type of residence in the assessment of their level of satisfaction with life.

\section{Limitations and suggestions for future studies}

This study has contributed to our knowledge of some of the variables that can influence life satisfaction. However, life satisfaction is a concept 
which is subjective and therefore can be influenced by a wide range of variables. The implication of this is that the determinants of life satisfaction are not universal but vary with nations, location and time. Therefore, additional variables should be considered for future research to allow for a deeper understanding of the subject matter.The participants for this study were selected from the metropolis alone, therefore,future studies should attempt a larger area. Also, all measures in this study were collected on a single structured questionnaire at one time and so a longitudinal study may be helpful for the purpose of establishing causal relationship.

\section{References:}

1. Adewuya, A. O., Afolabi, M. O., Ola, B. A., Ogundele, O. A., Ajibare, A. O., Oladipo, B. F., \& Fakande, I. (2010). The Effect of Psychological Distress on Medication Adherence in Persons with HIV Infection in Nigeria. Psychosomatics, 51(1), 68-73.

2. Alonso, W. (1964). Location and land use. Toward a general theory of land rent.

3. Aminzadeh, K., Denny, S., Utter, J., Milfont, T. L., Ameratunga, S., Teevale, T., \& Clark, T. (2013). Neighbourhood social capital and adolescent self-reported wellbeing in New Zealand: a multilevel analysis. Soc Sci Med, 84, 13-21.

4. Aremu, O., Lawoko, S., Moradi, T., \& Dalal, K. (2011). Socioeconomic determinants in selecting childhood diarrhoea treatment options in Sub-Saharan Africa: A multilevel model. Italian journal of paediatrics 37(13), 2-8.

5. Asiyanbola, R., Raji, B. and Shaibu, G. (2012), Urban liveability in Nigeria- A pilot study of Ago- Iwoye and Ijebu-Igbo in Ogun State. Journal of Environmental Science and Engineering Pp 1203-1213.

6. Ayeni B. (1982) Map of Land-use Patterns in Ibadan,Unpublished cited in Abumere S. I. (1994). Residential differentiation in Ibadan: Some sketches of an explanation, in Filan M. O.; Akintola F. O.; and Ikporukpo C. O. (eds.) Ibadan Region Rex Charles Publication Ibadan, pp. 72-84

7. Ballas, D., \& Dorling, D. (2013). The geography of happiness. In S. A. David, I. Boniwell, \& A.

8. C. Ayers (Eds.), The Oxford handbook of happiness (pp. 465-481). Oxford: Oxford University Press.

9. Becares, L., Cormack, D., \& Harris, R. (2013). Ethnic density and area deprivation: neighbourhood effects on Maori health and racial discrimination in Aotearoa/New Zealand. Soc Sci. Med, 88, 76-82. 
10. Berman, W.H., Heiss, G.E., \& Sperling, M.B. (1994). Measuring Continued Attachment to Parents. Psychological Report, 75, 171182.

11. Berry, B.J.L., \& Okulicz-Kozaryn, A. (2011). An Urban-Rural Happiness Gradient. Urban

12. Geography, 32 (6), pp. 871-883.

13. Boco, A. G. (2010). Individual and Community Level Effects on Child Mortality: An Analysis of 28 Demographic and Health Surveys in Sub-Saharan Africa. In DHS Working Papers No. 73 (Ed.). Calverton, Maryland, USA: ICF Macro.

14. Cervero, R., \& Duncan, M. (2002). Benefits of proximity to rail on housing markets: experiences in Santa Clara County. Journal of Public Transportation, 5(1).

15. Croft, J. (2003). Gating Communities for Children? The perennial problem of school choice, residential location and their (continuing) relationship with neighbourhood. Housing Studies, 19(6).

16. Deutsch-Burgner, K., Ravualaparthy, S., \& Goulias, K. (2014). Place happiness: Its constituents

17. and the influence of emotions and subjective importance on activity type and destination

18. choice. Transportation, 1-18.

19. De Vos, J.,Schwanen,T.,Van-Acker,V.\& Witlox,F.(2013).Travel and subjective wellbeing: A focus on findings, methods and future research needs.Transport Reviews,33(4),421-442.

20. Diener, E., Lucas,R.E., \& Schimmark, U.(2008). National Accounts of Wellbeing. Oxford, UK. Oxford University Press.

21. Dietz, R. (2002) The Estimation of Neighborhood Effects in the Social Sciences. Social Science Research 31, pp. 539-575.

22. DiMatteo, M.R. (2004). Social Support and Patient Adherence to Medical Treatment: A Meta-Analysis. Health Psychology 23(2), 207218.

23. Dittmann, J., \& Goebel, J. (2010). Your house, your car, your education: The socioeconomic

24. situation of the neighborhood and its impact on life satisfaction in Germany. Social Indicators Research, 96(3), 497-513.

25. Dolan, P., Peasgood, T., \& White, M. (2008). Do we really know what makes us happy? A review of the economic literature on the factors associated with subjective well-being. Journal of Economic Psychology, 29(1), 94-122.

26. Dung-Gwom, J. Y. (2007). Urban Renewal in Jos - Bukuru Metropolis. Paper Presented at the MCPD Workshops organized by 
the Nigerian Institution of Estate Surveyors and Valuers, October 25th, Jos, Plateau State, Nigeria.

27. Ekop, G. (2012). An assessment of the interrelationships among housing quality variable sets in Calabar metropolis.Journal of Geography and Regional Planning Vol.5(14), pp. 375-380.

28. Emmanuel, A. A., \& Akinbode, T. (2012). Communal Facilities in Coastal Settlements of Ondo State, Nigeria: Assessment of Community-Based Organisations Efforts using the Facility Index Model British Journal of Education, Society, and Behaviour, 2(2), 150-161.

29. Festinger, L. (1954). A Theory of Social Comparism Processes. Human Relations, 7, 117-140.

30. Florida, R., Mellander, C., \& Rentfrow, P. J. (2013). The happiness of cities. Regional Studies, 47(4), 613-627.

31. Frey, B., \& Stutzer, A. (2012). The use of happiness research for public policy. Social Choice and Welfare, 38(4), 659-674.

32. Galster, G, \& Sean P. K.(1995).The geography of metropolitan opportunity: A reconnaissance and conceptual framework. Housing Policy Debate 6, 1: 7-44.

33. George L.(2006) Perceived quality of life. In: Binstock R, George L , editors. Handbook of aging and the social sciences. 6th ed. Burlington, MA: Academic Press.

34. Gibbons, F.X.,\& Mccoy,S.B.(1991).Self-Esteem,Similarity and Reaction to Active versusPassive Downward Comparism. Journal of Personality and Social Psychology 60, 414-424.

35. Helliwell, J., Layard R. \& Sachs J., (2013). World Happiness Report. New York:

36. United Nations Sustainable Development Solutions Network.

37. Ho, M. Y., Cheung, F. M., and Cheung, S. F. (2008). Personality and life events as predictors of adolescents' life satisfaction: Do life events mediate the link between personality and life satisfaction? Social Indicators Research, 8: 475-471.

38. Horgas, A.L., Wilms, H.U., \& Baltes, M.M.(1998). Daily life in very old age: Everyday activities as expression of successful living. The Gerontologist.38:556-568.

39. Ibem, E.O \& Amole, D. (2014). Satisfaction with life in public housing in Ogun state,

40. Nigeria: a Research Note. Journal of Happiness Studies, 15 (1), pp. 495-501.

41. Ilesanmi, A.O. (2012), Housing, Neighbourhood Quality and Quality Of Life in Public Housing in Lagos, Nigeria, International Journal for Housing Science, Vol.36, No.4 Pp.231-240. 
42. Kahana, E., Lovegreen, L., Kahana, B., \& Kahana, M. (2003). Person, environment, and person-environment fit as influences on residential satisfaction of elders. Environment and Behavior, 35(3), 434-453.

43. Kauko, T. (2006). What makes a location attractive for the housing consumer? Preliminary findings from metropolitan Helsinki and Randstad Holland using the analytical hierarchy process. Journal of Housing and the Built Environment, 21(2), 159-176.

44. Layard, R. (2005). Happiness: Lessons from a new science. London: Allen Lane.

45. Leyden, K., Goldberg, A., \& Michelbach, P., (2011). Understanding the pursuit of happiness in

46. ten major cities. Urban Affairs Review, 47 (6), pp. 861-888.

47. Ludwig, J., Duncan, G. J., Gennetian, L. A., Katz, L. F., Kessler, R. C., Kling, J. R., \&

48. Sanbonmatsu, L. (2012). Neighborhood effects on the long-term well-being of low-income adults. Science, 337(6101), 1505-1510.

49. Luttmer, E. F. P. (2005). Neighbors as negatives: Relative earnings and well-being. The quarterly Journal of Economics, 120(3), 9631002.

50. Lyubomirsky, S. (2007). The how of happiness: A scientific approach to getting the life you want. New York: Penguin Press.

51. Lyyra, T.M. \& Heikkinen, R.L. (2006). Perceived Social Support and Mortality in Older People. The Journal of Gerontology, 61 (3): S147S152.

52. Mallo, D. M., \& Anigbogu, N. A. (2009). Housing Quality between Residential Neigbhourhood in Jos, Nigeria. Retrieved from www.gla.ac.uk/media/media129706.

53. McCrea, R., Marans, R., Stimson, R. \& Western, J., (2011). Subjective measurement of

54. quality of Life using primary data collection and the analysis of survey data. In: R.W.

55. Morrison, P.(2011). Local Expressions of Subjective Well-being: The New Zealand

56. Experience. Regional Studies, 45 (8), pp. 1039-1058.

57. Neugarten B.L., Havighurst R. J., \& Tobin, S. S. (1961). The Measurement of Life Satisfaction. Journal of Gerontology;16;134143.

58. Newson, J.T., \& Schulz, R. (1996). Social Support as a Mediator between Status and Quality of Life in Older Adults. Psychology and Aging, 11: 34-44. 
59. Nordbakke, S., \& Schwanen, T. (2013). Well-being and mobility: A theoretical framework and

60. literature review focusing on older people. Mobilities, 9(1), 104-129.

61. Olajuyigbe, A.E, Osakpolor, S. \& Adegboyega, S.A (2013), Assessment of Quality of Life

62. Using Geographical Information System Approach for Poverty Alleviation Decision-

63. Making, International Journal of Sustainable Land Use and Urban Planning Vol. 1 No.

64. 1, Pp. 1-20.

65. Ostir, G.V., Eschbach K., Markides, K.S., \& Goodwin, J.S. (2003).Neighborhood composition and depressive symptoms among older Mexican Americans. Journal of Epidemiology and Community Health.2003;57:987-992.

66. Oswald, A. \& Wu, S. (2010). Objective confirmation of subjective measures of human well-

67. being: Evidence from the U.S.A. Science, 327 (1), pp. 576-579.

68. Pedersen, P. J., \& Schmidt, T. D. (2011). Happiness in Europe: Cross-country differences in the

69. determinants of satisfaction with main activity. The Journal of SocioEconomics, 40(5), 480-489.

70. Peirce, R.S., Frone, M.R., Russell, M., Cooper, M.L., \& Mudar, P. (2000). A longitudinal model of social contact, social support, depression, and alcohol use. Health Psychology ;19(1):28-38.

71. Pinquart M., \& Soerensen S.(2000). Influences of socioeconomic status, social network, and competence on subjective well-being in later life: A meta-analysis. Psychology and Aging 15:187-224.

72. Poon, J. P. H., \& Shang, Q. (2014). Are creative workers happier in Chinese cities? The influence of work, lifestyle, and amenities on urban well-being. Urban Geography, 35(4), 567-585.

73. Sanni, L., \& Akinyemi, F. O. (2009).Determinants of households' residential districts’ preferences within metropolitan city of Ibadan, Nigeria. J Hum Ecol, 25(2), 137-141.

74. Sarason, B. R., Sarason, I. G., \& Gurung, R. A. R. (1997). Close personal relationships and health outcomes: A key to the role of social support. In S. Duck (Ed.), Handbook of personal relationships (2nd ed.,pp. 547-573). New York: Wiley.

75. Sharma, A., \& Malhotra, D. (2010). Socio-psychological correlates of happiness in adolescents. European Journal of Social Sciences, 12(4), 651-662.

76. Shaw, B.A.(2005). Anticipated support from neighbors and physical functioning during later life. Research on Aging.27(5):503-525. 
77. Shields,M.,Wheatley,P,S.,\&Wooden,M.(2009).Life satisfaction and the economic and social characteristics of neighbourhoods. Journal of Population Economics, 22(2), 421-443.

78. Shuhana, S., Nur Rasyiqah, A. H., \& Fatimah, I.B. (2012). Walkable Environment in Increasing

79. the Liveability of a City. ASEAN Conference on EnvironmentBehaviour Studies, Bangkok, Thailand.

80. Schulz,A., Williams,D.,Israel,B.,Becker,A.,Parker,E.,Sherman A., \& James J. (2000).Unfair Treatment, Neighborhood Effects, and Mental Health in the Detroit Metropolitan Area.

81. Journal of Health and Social Behavior. Vol. 41, No. 3 (Sep., 2000), pp. 314-332

82. Sirgy, M.J., \& Cornwell, T., (2002). How neighborhood features affect quality of life. Social Indicators Research, 59 (1), pp. 79-114.

83. Summer, H.C., \& Knight, P.A. (2001). How Do People with Different Attachment Style

84. Balance Work and Family. Journal of Applied Psychology, 86, 653663.

85. Thomas, P. A. (2010). Is it better to give or to receive? Social support and the well-being of older adults. The Journals of Gerontology: Series B: Psychological Sciences and Social Sciences, 65B, 351-357.

86. Tov,W.,\&Diener,E.(2007).Cultureandsubjectivewellbeing.InS.Kitayama\&D.Cohen

87. (Eds.),Handbookofculturalpsychology(pp.691713).NewYork:Guilford

88. Unger, A. (2013). Children's health in slum settings. Arch Dis Child. doi: 10.1136/archdischild-2011-301621

89. Vasquez, K., Durik, A.M., \& Hyde, J.S. (2002). Family and Work: Implication of Adult

90. Attachment Styles. Personality \& Social Psychology Bulletin, 28, 874-886.

91. Veenhoven, R. (1993). Happiness in nations: Subjective appreciation of life in 56 Nations 1946-1992. Rotterdam: Erasmus University Press.

92. Veenhoven, R. (2009). How do we assess how happy we are? Tenets, implications and tenability of three theories. In: A.K. Dutt and B. Radcliff, eds. 2009. Happiness, economics and politics: towards a multi-disciplinary approach. United Kingdom: Edward Elger Publishers, pp. 45-69.

93. Vizec, J. (2010). Guide to Governing Shared Community. Retrieved from www.dpcd.vic.gov.au/---/guide-to-governing-sharedcommunity. 
94. Wethington E., \& Kavey, A. (2000). Neighboring as a form of social integration and support. In: Moen P, Pillemer K, editors. Social integration in the second half of life. Baltimore: Johns Hopkins University Press. pp. 190-210.॥

95. Young, A.F, Russell, A., \& Powers, J.R. (2004). The sense of belonging to a neighbourhood: Can it be measured and is it related to health and well being in older women? Social Science \& Medicine.59(12):2627-2637.

96. Zimet, G.D., Dahlem, N.W., Zimet, S.G. \& Farley, G.K. (1988). The Multidimensional Scale of Perceived Social Support. Journal of Personality Assessment, 52, 30-41

97. Zunzunegui, M.V., Alvarado, B.E., Del-Ser, T., \& Otero, A. (2003). Social networks, social integration, and social engagement determine cognitive decline in community-dwelling Spanish older adults. Journal of Gerontology: Social Sciences. 58B(2):S93-S100. 